\title{
Addendum: Shaping the Cortical Landscape: Functions and Mechanisms of Top-Down Cortical Feedback Pathways
}

\author{
Edward Zagha* \\ Neuroscience Graduate Program, Department of Psychology, University of California, Riverside, Riverside, CA, United States
}

Keywords: feedback, motor preparation, attention, predictive coding, cortical circuits, functional connectivity

\section{An Addendum on}

OPEN ACCESS

Approved by:

Frontiers Editorial Office

Frontiers Media SA, Switzerland

*Correspondence:

Edward Zagha

edward.zagha@ucr.edu

Received: 23 November 2020

Accepted: 24 November 2020

Published: 11 December 2020

Citation:

Zagha E (2020) Addendum: Shaping

the Cortical Landscape: Functions

and Mechanisms of Top-Down

Cortical Feedback Pathways.

Front. Syst. Neurosci. 14:632485.

doi: 10.3389/fnsys.2020.632485
Shaping the Cortical Landscape: Functions and Mechanisms of Top-Down Cortical Feedback Pathways

by Zagha, E. (2020). Front. Syst. Neurosci. 14:33. doi: 10.3389/fnsys.2020.00033

Due to the addition of the published article to the Research Topic "Feed-forward and Feed-back Processing in the Cerebral Cortex: Connectivity and Function," the inclusion of the following Transparency Statement is required to ensure full transparency of the previous review process and to prevent any perception of a conflict of interest.

"This manuscript was published prior to the launch of the Research Topic" Feed-forward and Feed-back Processing in the Cerebral Cortex: Connectivity and Function "for which the handling Editor and the author are co-Editors. The handling Editor and the author confirm the absence of any collaboration during its review process."

Copyright $\odot 2020$ Zagha. This is an open-access article distributed under the terms of the Creative Commons Attribution License (CC BY). The use, distribution or reproduction in other forums is permitted, provided the original author(s) and the copyright owner(s) are credited and that the original publication in this journal is cited, in accordance with accepted academic practice. No use, distribution or reproduction is permitted which does not comply with these terms. 